\title{
Exploring the curriculum development in content and language integrated learning: A systematic review
}

\author{
Lingli Li ${ }^{1}$, Fuquan Huang ${ }^{2}$, Siyu Chen ${ }^{3}$, Leiqiong Pan ${ }^{4}$, Wenjie Zeng ${ }^{5}$, Xiaoqi Wu ${ }^{6}$ \\ ${ }^{1}$ School of Education Science and Technology, Guangdong Polytechnic Normal University, China \\ ${ }^{2,3,4,5,6}$ Center for Research and Development of Values Learning, South China Normal University, China
}

\begin{abstract}
Article Info
Article history:

Received May 2, 2020

Revised Sep 11, 2020

Accepted Oct 8, 2020

Keywords:

Content and language integrated learning Curriculum development Systematic review

ABSTRACT

Content and language integrated learning (CLIL) is a booming innovation pervading many educational settings. The global spread of CLIL is being practiced in classrooms the world over. Nevertheless, there is still a lack of systematic curricula for CLIL, despite its widespread adoption. Furthermore, the majority of teachers are implementing CLIL without the support of suitable published materials or resource banks. To explore and explain the curriculum development in CLIL, 281 studies from 2009 to 2019 were reviewed systematically, focusing on peer-reviewed English-language journals. We identified studies through using 'Content and Language Integrated Learning' and CLIL as the search terms in the ProQuest Research Library and EBSCO host databases. Selected articles were organized into five inquiry areas and analyzed thematically, inspired by the curriculum development model proposed by Pawlas and Oliva: 1) CLIL philosophy; 2) CLIL goals; 3) CLIL plan; 4) CLIL implementation; and 5) CLIL evaluation. Based on these themes, Boyer's scholarship of integration was introduced to propose a holistic model for CLIL curriculum development.
\end{abstract}

This is an open access article under the CC BY-SA license.

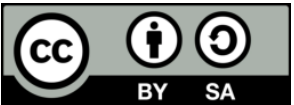

\section{Corresponding Author:}

Wenjie Zeng,

Center for Research and Development of Values Learning,

South China Normal University,

Guangzhou city, Guangdong, China.

Email: zengwj@scnu.edu.cn

\section{INTRODUCTION}

The concept of content and language integrated learning (CLIL) was first coined as a term in 1994 and launched in 1996 [1]. Emerging as a major curriculum innovation, CLIL refers to 'a dual-focused educational approach in which an additional language is used for learning and teaching of both content and language' [2]. Today, CLIL has spread fast and has been adopted widely in schools worldwide.

With the proliferation of CLIL, its curriculum development (CD) has received considerable attention from scholars and practitioners alike [3]. CD is a process providing a means for ordering and directing learning experiences' [4], allowing certain educational aims to be realized at school level. CLIL CD is a vehicle for building high quality programming, to realize the integration of content learning and language learning. It is a complex process to develop a CLIL curriculum because many factors and aspects must be considered [5], such as specific criteria, specified goals, specifically designed materials, and systematic evaluation. Nevertheless, there is still a lack of general guidelines for CLIL CD [6-8].

In 2010, Coyle, Hood, \& Marsh published a book titled CLIL: Content and Language Integrated Learning. They provided an ample gamut of curriculum models [9]. This book is a landmark synthesis of the studies done in and before 2009. Thus, taking the year 2009 as the dividing point, some subsequent reviews 
have been conducted to examine CLIL development. The issues addressed in these reviews have included: 1) theories for CLIL [10, 11]; 2) CLIL implementation [12-15]; and 3) CLIL evaluation [1, 16]. These works discussed CLIL CD piecemeal, and most of them provided syntheses of research using traditional (narrative) methods, with the exception of some recent studies, i.e. Graham, et al. [17] and Goris, et al. [18].

The authors have attempted to take account of these issues in this systematic review, which aimed to achieve the broadest possible coverage of CLIL studies done from 2009 to 2019, published in peer-reviewed English-language journals. To provide focus in the review, five inquiry areas have been selected: CLIL philosophy, CLIL goals, CLIL plan, CLIL implementation, and CLIL evaluation. These in turn led to five main questions in relation to CLIL CD: 1) What theories are identified for establishing CLIL philosophy?; 2) What goals are recognized for CLIL?; 3) How do programmers design a CLIL plan?; 4) What has been taken into account when implementing CLIL?; 4) What has been taken into consideration when evaluating CLIL?

In sum, an overview of CLIL CD is an important thing to be considered. Therefore, we systematically reviewed 281 CLIL studies using the well-known CD model by Pawlas and Oliva [19], and constructed a CLIL CD model inspired by Boyer's scholarship of integration (SOI) [20], in order to inform CLIL researchers and practitioners.

\section{RESEARCH METHOD}

A systematic review was conducted to identify and classify research related to CLIL CD. The systematic review, as an evidence-based method, aims to provide systematic, transparent approaches for gathering, synthesizing, and appraising research findings and minimizing bias [21]. Adapting the guidelines proposed by Tranfield, Denyer, and Smart [22], this study was carried out by identifying keywords and search strategies, selecting studies, data extraction, and data synthesis.

\subsection{Identifying keywords and search strategies}

A comprehensive search of authoritative and scholarly electronic databases (ProQuest Research Library and EBSCOhost) was undertaken to obtain all literature from January 1, 2009 to February 19, 2019 (the authors' cutoff point for data collection). To make sure the studies did in fact fall into the domain of our review, we focused on the studies that explicitly used the term 'Content and Language Integrated Learning' (between quotation marks to ensure that the whole terminology of content and language integrated learning was used as a search term) and its abbreviation 'CLIL', which needed to be mentioned in the abstract or title.

\subsection{Selecting studies}

In this step, we selected studies by using the following criteria: First, we applied the search terms to each of the above two databases. Only studies published in peer-reviewed English language journals on CLIL were included: 766 studies were retrieved in total (Figure 1). Second, we eliminated repeated studies, which left us with 416 . Finally, we selected the studies by scanning each one individually, excluding book reviews, symposiums, editorials, literature reviews, and non-CLIL articles, reducing the sample to 281 studies.

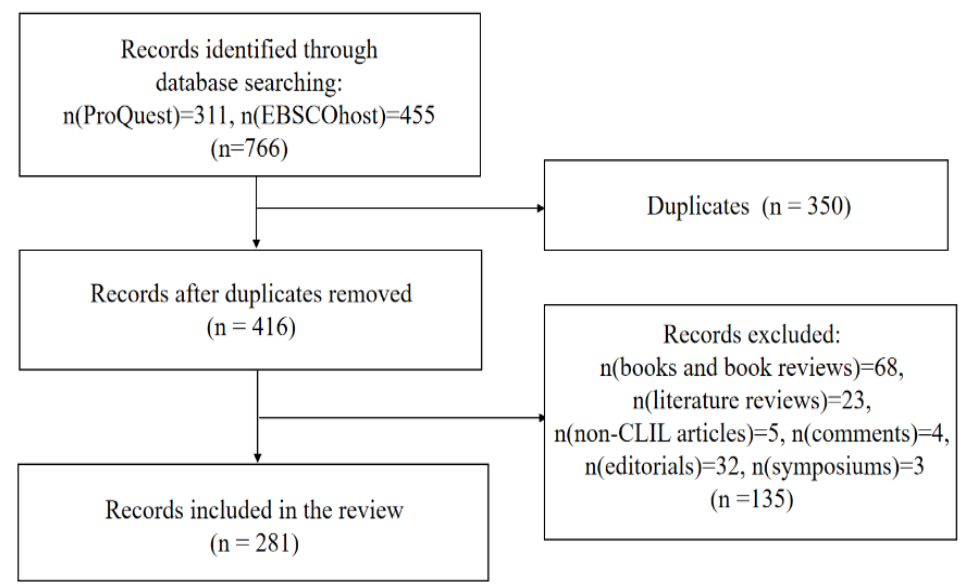

Figure 1. Flowchart of search process 


\subsection{Data extraction}

Our aim was to answer authoritatively how CD occurs in CLIL. Inspired by the model for CD developed by Pawlas and Oliva [19], we extracted the data from each study regarding the five inquiry areas: CLIL philosophy, CLIL goals, CLIL plan, CLIL implementation, and CLIL evaluation (Supplementary File 2 Online). We were interested in CLIL philosophy because it can guide programmers to articulate their orientations and beliefs about CLIL. The establishment of philosophy is the clarification of beliefs, and it usually goes with theories [23]. For this reason, we explored the theories informing the CLIL philosophy discussed in the literature. We intended to find CLIL goals as these can inform curriculum practitioners to state the learning outcomes of CLIL programs. Just as Pawlas and Oliva argued that no clear distinction could be made between goals and objectives [19], we did not distinguish CLIL goals and objectives, but make them convergence. Precise CLIL goals were largely missing in the literature. Hence, this manuscript used a method of assessment to determine CLIL goals: i.e. if the speech was assessed relative to learning outcomes (e.g. improving language abilities, or the purpose of a specific course), we extracted them as CLIL goals.

The term 'CLIL plan' refers to the creation of a CLIL curriculum. A curriculum plan is usually presented as a proposal for the programmers [19], which is underpinned by some frameworks or models. Hence, we were interested in the frameworks or models informing the CLIL plan discussed in the literature. Curriculum implementation is the translation of plans into action. The effective implementation of certain curricula is influenced by multiple factors, including time, in-service training, other forms of people-based support, and strategies [24]. Therefore, we extracted the factors influencing CLIL implementation explored in the literature. By curriculum evaluation we meant the assessment of programs, processes, curricular products, and evaluation techniques [19]. Our focus in this inquiry area was on the evaluation aspects that researchers suggested to be considered or mentioned in their research.

\subsection{Data synthesis}

We synthesized the data extractions from each study. That is, we compared the extraction records for all the studies in our CLIL CD dataset, and carried out a thematic analysis. Topics were operationalized inductively as the data were analyzed. Five topics were identified: Theories for CLIL philosophy, the statement of CLIL goals, frameworks for CLIL plan, factors of CLIL implementation, and aspects of CLIL evaluation. Descriptions in the data related to each topic were classified and labels were assigned to identify underlying themes within each topic. This was an iterative process, as we reviewed and critically evaluated the labels regularly. The detailed analysis is presented in the following section.

\section{RESULTS}

The examination of 281 studies led to the identification of themes for CLIL CD. The key words and count displayed in the following tables were obtained from the data synthesis, and the results were reported in response to the research questions.

\subsection{Theories for CLIL philosophy}

The development of CLIL has been based on a solid theoretical background [25]. Our search yielded 75 studies mentioning theories, which were referred to 96 times totally. We identified four theories informing the establishment of CLIL philosophy in our literature review (Table 1). We used the term language educational theory-derived to describe CLIL philosophy which is based explicitly on systematic functional linguistics (SFL) related theories, and second language acquisition (SLA) related theories. Bilingual learning theory-derived refers to CLIL philosophy assuming language learning and content learning are integrated, and discussing the relationship between target language learning and mother-tongue learning. Construction theory-derived describes CLIL philosophy taking students as active doers in their learning processes, making them competent language users, and stressing mediation, scaffolding, communication, and meaning. Cognition theory-derived refers to CLIL philosophy considering language as inextricably tied to concept development.

In short, the center of these theories is that content and language are learned most effectively for active construction in meaningful, purposeful, cultural and academic contexts. Table 1 gives an overview of the four theories for CLIL philosophy we identified in the literature. The first column demonstrates the emphasis on CLIL philosophy, while the second column illustrates the specific theories and their statement counts. As Table 1 shows, language educational theory-derived philosophy seems to dominate the field. 
Table 1. Theories for CLIL philosophy

\begin{tabular}{ll}
\hline CLIL philosophy emphasis & \multicolumn{1}{c}{ Associated theories and their statement count } \\
\hline $\begin{array}{l}\text { Language educational } \\
\text { theory-derived }\end{array}$ & $\begin{array}{l}\text { SFL(22); genre theory(2); input hypothesis(5); second language acquisition theory)(4); interaction } \\
\text { approach(4); iceberg model(2); output hypothesis(2); monitor model(1); natural approach(2) }\end{array}$ \\
$\begin{array}{l}\text { Bilingual theory-derived } \\
\text { Basic interpersonal communicative skills and cognitive academic language proficiency (BICS and } \\
\text { CALP)(17); iceberg model(2); common underlying proficiency (CUP) theory(1) }\end{array}$ \\
$\begin{array}{l}\text { Construction theory- } \\
\text { derived }\end{array}$ \\
$\begin{array}{l}\text { Social/cognitive constructivism(st)(12); didactic transposition(2); social-cultural theory(15); } \\
\text { Vygotsky's zone of proximal development(1) }\end{array}$ \\
$\begin{array}{l}\text { Cognitivist views/Bloom's revised taxonomy of thinking skills(2); cognitive load theory/cognitive } \\
\text { psychology(2); cognitive psychology(2) }\end{array}$ \\
\hline
\end{tabular}

\subsection{The statement of CLIL goals}

In the literature, we identified 141 studies mentioning CLIL goals, which were mentioned 177 times. Dalton-Puffer and Smit stated that experts had formulated an array of goals for CLIL [26]. According to the data extraction, there were $64 \mathrm{key}$ words describing CLIL goals, and we classified them into six themes. Language knowledge and competence, the initial focus of CLIL, is related to learners' proficiency in communication and multilingualism. Content knowledge and competence refers to acquiring knowledge, skills and understandings of subjects, themes or topics. Intercultural knowledge and competence refer to international understanding and appropriate behaviors in intercultural situations. Cognitive development describes the capacity to think. Affective development is the development of emotion, which is important for sustainable learning and regarded as powerful influences on learning. Learning skills describes the skills of learning to learn. Table 2 gives an overview of the six themes for CLIL goals identified in the literature. It demonstrates that most goals are related to language knowledge and competence, mentioned 134 times. This may be because researchers hold that CLIL is a prerequisite for enhancing learners' language learning [27]. The second column of Table 2 shows the key words used in the literature to describe CLIL goals and their statement count.

Table 2. The statement of CLIL goals

\begin{tabular}{|c|c|}
\hline CLIL Goals & Key words and their statement count \\
\hline $\begin{array}{l}\text { Language } \\
\text { knowledge } \\
\text { competence }\end{array}$ & $\begin{array}{l}\text { Multilingualism (plurilingualism)(51); target (English/foreign) language proficiency(33); communicative } \\
\text { ability (communication)(22); language proficiency (competence or ability)(10); academic language (4); } \\
\text { interaction ability (3); bilingualism(bilingual) (3); language skill(2); language knowledge (1); linguistic } \\
\text { diversity(2); basic language skill(2); subject specific target language terminology (1) }\end{array}$ \\
\hline $\begin{array}{l}\text { Intercultural } \\
\text { knowledge and } \\
\text { competence }\end{array}$ & $\begin{array}{l}\text { Intercultural (pluricultural) competence(10); intercultural knowledge and understanding(3); cross- } \\
\text { cultural understanding (commutative competence) (2); mutual understanding(2); subject specific } \\
\text { (economic) target language (2); intercultural awareness(1); cultural awareness(1); cultural and diversity } \\
\text { awareness(1); cultural sensitivity(1); intercultural communication and acceptance(1); inter-cultural } \\
\text { awareness(1); intercultural knowledge(1); cultural exchange(1); right interpersonal skills(1); democratic } \\
\text { citizenship and social cohesion(1); intercultural communication skills(1); new subject concepts(1) }\end{array}$ \\
\hline Content & (Subject) content knowledge(5); academic content (academic achievement in subjects(3); content \\
\hline $\begin{array}{l}\text { knowledge and } \\
\text { competence }\end{array}$ & $\begin{array}{l}\text { knowledge(2); academic skills (2); content knowledge and skills(1); deeper content learning(1); content } \\
\text { comprehension(1); content learning(1); content skills(1); academic knowledge(1); deeper understanding } \\
\text { of the subject matter(1); content competence(1); subject competence(1); subject content(1); knowledge } \\
\text { across the school curriculum (science, mathematics, social studies) (1) }\end{array}$ \\
\hline $\begin{array}{l}\text { Cognitive } \\
\text { development }\end{array}$ & $\begin{array}{l}\text { Cognitive skills(3); cognition(3); cognitive abilities(1); higher cognitive level(1); cognitive } \\
\text { advantages(1); evaluate or appraise subject content(1); higher-order thinking(1); processing } \\
\text { information(1); cognitive flexibility(1) }\end{array}$ \\
\hline $\begin{array}{l}\text { Affective } \\
\text { development }\end{array}$ & $\begin{array}{l}\text { Motivation(12); attitudes(6); interest (4); self-confidence(4); enhance students' psychological, emotional, } \\
\text { and social wellbeing(1) }\end{array}$ \\
\hline Learning skill & $\begin{array}{l}\text { Learners' autonomy(6); learning to 'learn' competence(3); cooperative learning (teamwork)(2); skills } \\
\text { development(1); holistic learning(1); improve implicit and incidental learning abilities(1) }\end{array}$ \\
\hline
\end{tabular}

\subsection{Frameworks for CLIL plan}

Some of the bad experiences with CLIL have been due to a lack of planning [28]. To guide programmers to design CLIL plan effectively, researchers have come up with or adapted various frameworks and models. Our search yielded 63 studies concerning with CLIL plan. In total, there were 11 frameworks (models), with 70 mentions. The frameworks (models) in our dataset could be grouped into two dimensions: 'What' of CLIL framework and 'how' to integrate framework.

The 'what' of CLIL framework refers to what should be the fundamental elements when designing CLIL plan, such as the 4Cs framework, which advises taking content, communication, cognition, and culture into consideration when designing. The 'how' to integrate framework is concerned with guiding programmers with the approaches or processes to integrate content and language. For example, sheltered instruction observation protocol (SIOP), is a model guiding programmers on how to integrate content and language 
based on students' background and educational needs [29]. Table 3 illustrates the specific frameworks (models) and their statement count.

Table 3. Frameworks for CLIL plan

\begin{tabular}{ll}
\hline \multicolumn{1}{c}{ Dimension } & \multicolumn{1}{c}{ Frameworks (models) and their instruction count } \\
\hline 'What' of CLIL & 4Cs framework(45); language triptych(10); knowledge structure(4) \\
'How' to & Core CLIL construct(3); Cummins' quadrant (matrix)(2); CLIL matrix(1); SIOP(1); The Graz group's pluriliteracies \\
integrate & framework(1); CLIL pyramid(1); modified hierarchical model(1); Lin's framework of multiple bridging resources(1) \\
\hline
\end{tabular}

\subsection{Factors of CLIL implementation}

CLIL has been considered as a fruitful educational approach, however, the success of its curriculum implementation may not be straightforward [30]. Our research yielded 143 studies discussing factors relating to CLIL implementation. The factors influencing the implementation of CLIL discussed in our dataset can be classified as CLIL teacher education, CLIL stakeholders' support and CLIL implementation strategies.

\subsubsection{CLIL teacher education}

CLIL teacher education refers to programs designed to equip (prospective) teachers with the knowledge, attitude, behaviors, and skills for carrying out CLIL activities. Our research yielded 55 studies of CLIL teacher education, which was explored by two dimensions discussed 138 times in all, viz., approaches to CLIL teacher education, and CLIL teachers' competence (Table 4). Approaches to CLIL teacher education refers to the ways of preparing CLIL teachers. CLIL teachers' knowledge and competence refers to the knowledge, skills and behaviors of teachers needed to conduct CLIL. There was more research on CLIL teachers' competence than on the approaches for preparing CLIL teachers.

Table 4. CLIL teacher education

\begin{tabular}{ll} 
CLIL teacher education & \multicolumn{1}{c}{ Key words and their discussion count } \\
\hline $\begin{array}{l}\text { Approaches to CLIL } \\
\text { teacher education }\end{array}$ & In-service teachers' training(22); pre-service teacher preparation(13) \\
& $\begin{array}{l}\text { General knowledge and competence: Teaching methods (theory/ pedagogy) and learning strategies(17); } \\
\text { assessment/ evaluation(8); classroom management (organization)(9); material (curriculum) design(9); }\end{array}$ \\
& knowledge/ understanding/ methodology of CLIL(7); pedagogical content knowledge(3); lesson plan(3); \\
interpersonal, and collaborative competence(2); ongoing professional development(2); scientific & knowledge(1); reflective and developmental competence(1); knowledge for teaching(1); general teaching \\
CLIL teachers' & competence(1); TK(1); TPCK(1); Language-related knowledge and competence: Language knowledge \\
knowledge and & (proficiency awareness)(14); second language methodology /pedagogy)(5); cultural competence(3); ELT/L2 \\
competence & theories(2); language knowledge for content teaching(2); linguistic features in their subject teaching(1); \\
& Content-related knowledge and competence: Content (subject) knowledge (9); content pedagogy(1)
\end{tabular}

\subsubsection{CLIL stakeholders' support}

CLIL stakeholders' support means a range of stakeholders' assistance for the implementation of CLIL, which was mentioned by 36 studies, and 47 times in all. Table 5 shows that support was from schoolexternal stakeholders and school personnel stakeholders. School-external stakeholders are those who are not school staff, but close to education, such as parents. School personnel stakeholders refer to any persons working in a school, whose support is the foundation for implementing CLIL smoothly.

Table 5. CLIL stakeholders' support

CLIL stakeholders' support Key words and their discussion count

School-external stakeholders' support Government's support (policy making)(19); parents' involvement/ support/ participation(9)

School personnel stakeholders'support Colleagues' support(10); management team's/ program directors'/headteachers'/ school administrators' support(7); language assistants' participation(2)

\subsubsection{CLIL implementation strategies}

CLIL implementation strategies imply the methods used to carry out CLIL effectively. Our research yielded 88 studies of CLIL implementation strategies, and this study stratified 43 strategies which were introduced 127 times, viz., general learning strategies, language learning strategies, and specific content learning strategies. General learning strategies are the methods developed for supporting learning, i.e. 
cooperative learning. Language learning strategies are those strategies used to make language learning easy. Specific content learning strategies refer to those methods created for assisting specific content learning. We found language learning strategies were used most, 66 times in all. Table 6 gives an overview of the three implementation strategies identified in the literature.

Table 6. Implementation strategies of CLIL

\begin{tabular}{ll}
\hline Implementation strategies & \multicolumn{1}{c}{ Key words and their discussion count } \\
& $\begin{array}{l}\text { Code switching/ translanguaging/ language alternation/ the role of L1(22); task-based } \\
\text { learning/teaching(19); genre-based teaching(3); (content-based structured) input } \\
\text { enhancement(2), negotiation strategies(1); communication language teaching(1); lexical } \\
\text { bundles(1); multiliteracies approach(1); noticing(1); syllabification(1); morphological cues(1); } \\
\text { think-pair-share(1); vocabulary-building strategies(1); questioning techniques(1); immediate } \\
\text { Language learning } \\
\text { strategies }\end{array}$ \\
& $\begin{array}{l}\text { correction(1); pushed output(1); the use of leaner inner speech(1); content \& languages [L1/L2] } \\
\text { ICT(19); co-teaching/team teaching(14); cooperative learning(5); project work(4); game-based }\end{array}$ \\
& $\begin{array}{l}\text { learning (gamification) (3); portfolio(2); role play(2); story-telling(1); problem-solving } \\
\text { teaching(1); experimenting(1); modelling(1); group and pair work(1); reading to learn(1); } \\
\text { argument(1); charts, diagrams, and drawings(1); lean thinking methodology(1) }\end{array}$ \\
General learning & Experiment implementation(2); comics(1); announcement imitation(1); hypothesis \\
strategies & formation(1); report writing(1); field trips(1)
\end{tabular}

\subsection{Aspects of CLIL evaluation}

There were 189 studies introducing the evaluation of CLIL, and we identified two aspects discussed in the literature: CLIL evaluation objectives and CLIL evaluation techniques.

\subsubsection{CLIL evaluation objectives}

CLIL evaluation objectives refer to what are to be evaluated in CLIL. 29 CLIL evaluation objectives were explored 241 times by 190 studies in our dataset. These evaluation objectives were classified into four domains: learners' learning, teachers' performance, curriculum materials and the evaluation program itself. Table 7 shows that learners' learning was the evaluators' greatest concern, with 179 times of this in all, including the evaluation of language learning, content learning, learners' attitude, learners' motivation, classroom interaction, cognitive development, cultural awareness, learners' engagement, and learners' selfconcept. Of these, learners' language learning was evaluated the most, 81 times; this was not only concerned with learners' target language learning, but also with their mother tongue learning [31]. As well, we found that CLIL objectives for evaluating learners' learning corresponded with CLIL goals. Evaluation of teachers' performance was another concern of CLIL stakeholders, with this being mentioned 38 times. Evaluation of curriculum materials was mentioned 13 times. Literature referring to the evaluation program itself, included evaluations of the beneficial effects of CLIL, CLIL concept evaluation, CLIL evaluation checklists, and assessment approaches. These were evaluated 12 times, and the evaluation of beneficial effect has attracted heated discussion among scholars [32-34]. Table 7 demonstrates the detailed information about CLIL evaluation objectives.

Table 7. CLIL evaluation objectives

\begin{tabular}{ll}
\hline CLIL evaluation objectives & \multicolumn{1}{c}{ Key words and their evaluation count } \\
\hline \multirow{2}{*}{ Learners' learning } & $\begin{array}{l}\text { Language learning(81); content learning(25); learners' attitude(18); learners' motivation(16); } \\
\text { classroom interaction(11); cognitive development(10); culture awareness(5); learners' } \\
\text { engagement(3); learners' self-concept(1); learners' autonomy(1); learning process (reading } \\
\text { strategies/ cooperation/ clarification requests/learning strategies)(7) } \\
\text { Teachers' attitude(16); teaching quality(9); teachers' (language) competence(5); teachers' } \\
\text { competence of classroom climate creating(2); competence of collaboration with other teachers(1); } \\
\text { affordances of language in curriculum(1); teachers' technology pedagogical content knowledge(1); } \\
\text { teachers' motivation(1); teachers' CLIL knowledge(1); the pedagogy of CLIL teachers(1) }\end{array}$ \\
& $\begin{array}{l}\text { Lesson plans(6); material development(4); coursebook(2); course syllabi evaluation(1) } \\
\text { Curriculum materials }\end{array}$ \\
CLIL beneficial effects evaluation(6); CLIL concept evaluation(2); CLIL evaluation checklist(2); \\
\hline
\end{tabular}

\subsubsection{CLIL evaluation techniques}

There were 183 studies introduced CLIL evaluation techniques in our study. These could be classified into two kinds: quantitative-driven techniques and qualitative-driven techniques. The former refers to the systematic empirical investigation of CLIL by statistical, mathematical or computational techniques, which was mentioned 137 times totally. The latter refers to the method used to deal with phenomena which is 
difficult or impossible to quantify mathematically, mentioned 142 times. Table 8 indicates that researchers used more qualitative-driven techniques than quantitative-driven ones.

Table 8. CLIL evaluation techniques

\begin{tabular}{cl}
\hline CLIL evaluation techniques & \multicolumn{1}{c}{ Key words and their usage count } \\
\hline Quantitative-driven techniques & $\begin{array}{l}\text { Questionnaire(75); test(62) } \\
\text { Interview(38); observation(33); video(21); essay(9); task(11); content analysis(7); report(5); } \\
\text { Qualitative-driven techniques } \\
\text { documents analysis(7); narration (2); portfolio(2); journal(2); classroom discourse } \\
\text { analysis(2); conversation analysis(2); dictation(1); field note(1); language teaching wall(1) }\end{array}$ \\
\hline
\end{tabular}

\section{DISCUSSION}

Based on the results of this literature review and according to Boyer's SOI notions [20], we were able to construct a holistic CLIL CD model. The model is presented here and its elements are introduced.

\subsection{Proposal of a holistic model of CLIL CD}

The review of 281 peer-reviewed English studies generated a plethora of understandings in the inquiry areas of philosophy, goals, plan, implementation and evaluation for CLIL CD. Table 9 gives a schematic overview in relation to each topic, and shows that each inquiry area identifies a range of themes with considerable variation for CLIL CD. That is, CLIL programmers are faced with a multitude of possible elements in their CD, and it seems difficult for them to develop CLIL curriculum systematically. To enable CLIL teachers and designers to develop their own curriculum, we synthesized and interpreted the existing evidence in order to provide a comprehensive overview of the current understanding of CLIL CD, which fits into Boyer's SOI [20]. Thus, based on the findings, we took SOI and connected it profitably with CLIL to ground an argument for constructing a model for CLIL CD.

Table 9. Thematic overview of CLIL philosophy, goals, plan, implementation, evaluation found in the

\begin{tabular}{|c|c|c|c|c|}
\hline \multicolumn{5}{|c|}{ literature } \\
\hline $\begin{array}{l}\text { Language educational } \\
\text { theory } \\
\text { Bilingual learning } \\
\text { theory } \\
\text { Constructivism } \\
\text { Cognitive theory }\end{array}$ & $\begin{array}{l}\text { Language knowledge } \\
\text { and competence } \\
\text { Content knowledge and } \\
\text { competence } \\
\text { Intercultural knowledge } \\
\text { and competence } \\
\text { Cognitive development } \\
\text { Learning skills } \\
\text { Affective development }\end{array}$ & $\begin{array}{l}\text { 'What' of CLIL } \\
\text { 'How' to integrate }\end{array}$ & $\begin{array}{l}\text { CLIL teacher education } \\
\text { CLIL stakeholders' support } \\
\text { CLIL implementation } \\
\text { strategies }\end{array}$ & $\begin{array}{l}\text { CLIL evaluation objectives } \\
\text { CLIL evaluation techniques }\end{array}$ \\
\hline
\end{tabular}

Scholars assume three dominant notions for SOI: Interpretation, interdisciplinarity, and integration [35]. Interpretation is rooted in the findings delivered by original research, and asking 'What do the findings mean? Is it possible to interpret what's been discovered in ways that provide a larger, more comprehensive understanding?' [20]. Interdisciplinarity means bringing diverse fields together and bringing new perspectives and insight to bear on research findings [20]. Integration means the interdisciplinary critical analysis fitting one's own research or the research of others into larger intellectual patterns [20].

Applied to CLIL, the notions of SOI provide a basic framework for its CD. Generally, curriculum is developed by following the core features of a specific approach. In other words, the CD for CLIL has unique characteristics. CLIL has been argued to be a new paradigm of translanguaging to transcend traditional approaches [36], and it is integrative and interdisciplinary by nature [37]. In this way, based on SOI and the characteristics of CLIL, this study has proposed a holistic model of CLIL CD.

The first notion, 'interpretation', is associated with interpreting the findings from the synthesis of the literature and attempting to provide a comprehensive understanding of CLIL CD. Table 9 shows that the themes are visualized as separate from one another, but in fact they interact in the process of CLIL CD. For example, there may be interaction between CLIL goals and CLIL evaluation objectives. When the focus of CLIL goals is on content knowledge and competence, the programmers may evaluate learners' content learning. The design of CLIL goals, plan, implementation and evaluation may be influenced by the theoretical perspective on CLIL philosophy. The findings also indicate that CLIL is not only the integration of content learning and language learning, but the integration of many factors. For example, when planning CLIL, programmers need to take context, cognition and culture as well as content and language into account. 
A second notion, 'interdisciplinarity', is concerned with linking content discipline, language discipline, and other related disciplines. First, CLIL is not influenced by one theory, but by the fusion of many, such as language educational theories, constructional theories, and cultural learning theories [38-40]. Thus, when stating CLIL philosophy, there is a need to consider deriving its theoretical foundation from different theories. Second, with regard to the strategies for CLIL implementation, interdisciplinarity indicates that programmers need particular strategies, which can be derived from an integration of the strategies used in language discipline (e.g. communication strategies), the strategies used in a specific subject discipline (e.g. field trips for geography), and the general learning strategies (e.g. cooperative learning). Third, pre-service or in-service education programs are needed to prepare CLIL teachers who are competent both in language and content in addition to general pedagogy [41, 42].

A third notion is of 'integration'. Integration here is beyond that of content and language, and it has five domains of meaning in CLIL CD. It is suggested that the first domain of integration is that of the current theoretical underpinnings for CLIL [43], through which the concept 'holistic learning philosophy' comes to being, attempting to integrate the assumptions of SFL, SLA, bilingual learning theories, construction, cognitive theories, and other theories of different fields. The second domain is the integration of CLIL goals. CLIL is not concerned solely with content and language, its goals have a broader dimension [44], including interculture, cognition, learning skills and affection. These could be integrated as explicit, implicit, and emancipatory goals based on Yang's holistic learning theory [45]. The third domain of integration is to combine designing both the elements and approaches of integration when planning CLIL. According to Coyle [38], CLIL programmers need to know 'how' to integrate (approaches) as well as the 'what' of CLIL (the fundamental elements). The fourth domain relates to three factors influencing the implementation of CLIL. For one thing, there is a call for preparing competent teachers to promote CLIL successfully [46]. For another, appropriate strategy is an integral part of the implementation factor [47], and support from stakeholders is also a contributing factor to CLIL implementation [48]. In short, these three factors should be integrated for the success of implementing CLIL. The last type of integration is concerned with the evaluation of CLIL. It has been argued that it would be easier if CLIL evaluators know what should be evaluated, and how to evaluate [49]. That is to say, programmers need to consider evaluators, evaluation objectives, and evaluation techniques when evaluating CLIL.

In sum, based on the themes and SOI notions, a holistic model for CLIL CD was constructed. This model is fundamentally at the nexus of: 1) establishment of holistic learning philosophy, 2) statement of holistic learning goals, 3) design of holistic CLIL plan, 4) multi-focused implementation of CLIL, and 5) multi-focused evaluation of CLIL (Figure 2). These five stages interact with different elements dynamically. The core elements of the model will be discussed in the following section.

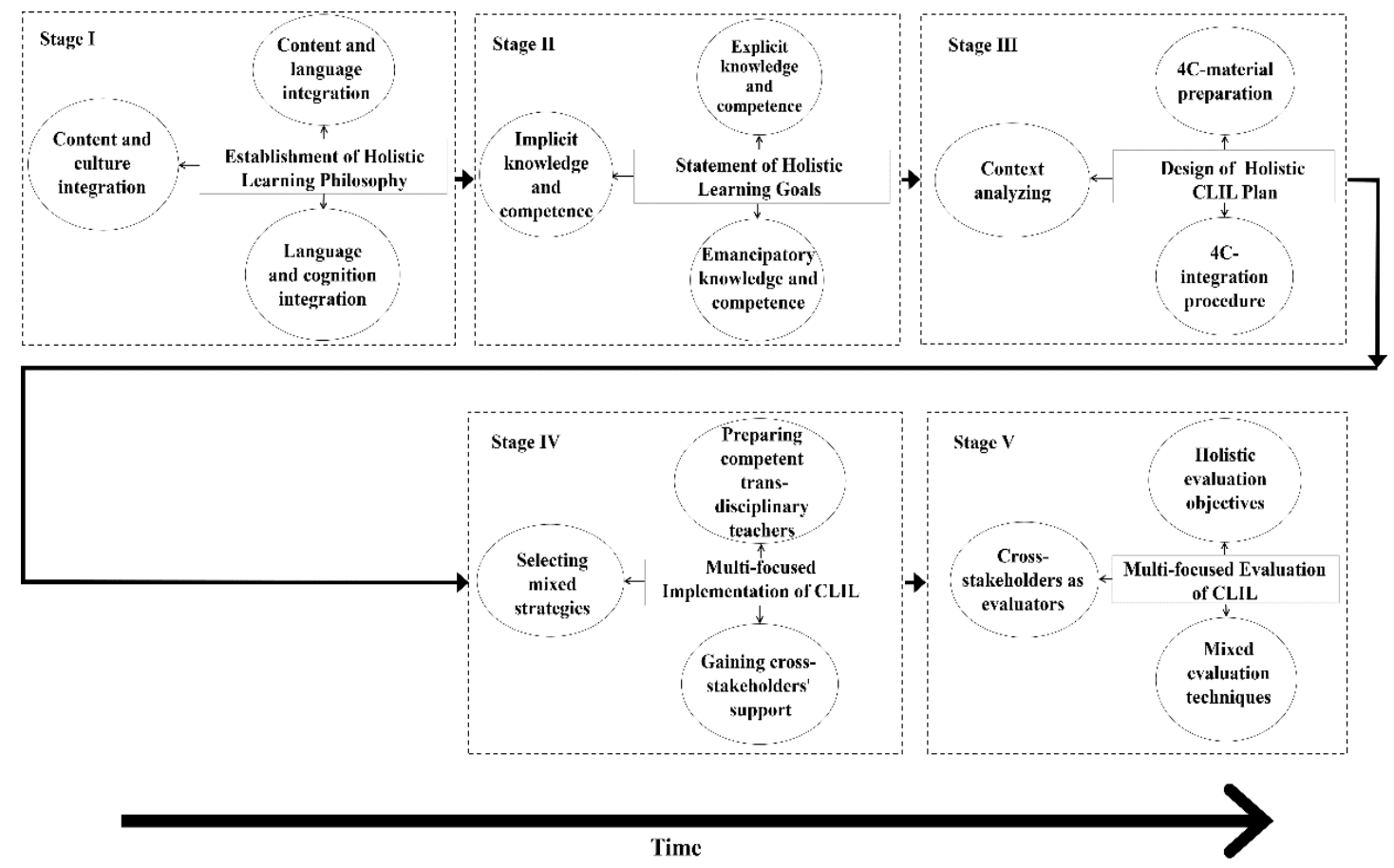

Figure 2. Holistic model of CLIL CD 


\subsection{Elements in the holistic model of CLIL CD}

After roughly summarizing the elements that received attention from a selection of 281 studies for the five stages of CLIL CD and describing the construction of the holistic model, this section introduces the elements for each stage. Stage one refers to the establishment of holistic learning philosophy. The holistic learning philosophy is the results of integrating different theories. It explains CLIL CD as a holistic process of continuously building the bridges between language-related and content-related disciplines. The establishment of holistic learning philosophy includes three elements: 'Content and language integration', 'language and cognition integration', and 'content and culture integration'. 'Content and language integration' philosophy suggests that language and content are inseparable, that is, 'language is a system that relates what is being talked about (content) and the means used to talk about it (expression)' [50]. By the philosophy of 'language and cognition integration' we mean that language learning and cognitive development go hand in hand, different language refers to different thinking, and the thinking collision in mother tongue learning and target language learning can broaden learners' thinking horizons, which can improve their cognitive development. 'Content and culture integration' philosophy describes the interaction between content and culture. Content is never value neutral, but always related to specific cultural orientation.

Stage two is the statement of holistic learning goals: Explicit, implicit, and emancipatory knowledge and competence goals. Explicit knowledge and competence goals refer to clear and certain mental apprehensions of language and content knowledge, and developing language abilities and content skills, which are the core of CLIL goals. Implicit knowledge and competence goals are personal, context-specific abilities, including intercultural understanding and cognition. Emancipatory knowledge and competence goals are about the development of learners' emotions and learning skills, which are to support content learning, language learning, intercultural learning and cognitive development.

Stage three refers to the design of holistic CLIL plan. A holistic CLIL plan consists of context analysis, 4C-material preparation, and 4C-integration procedure. Context analysis plays a vital role when planning CLIL, as it draws attention to the identity, flexibility and the local curriculum for fitting CLIL into the specific constituent. 4C-material preparation requires programmers to prepare materials by taking content, communication (language), culture, and cognition into account based on the context being analyzed. 4C-integration procedure means that programmers need to consider how to integrate content, communication (language), culture, and cognition effectively and naturally during designing activities, tasks, or materials.

Stage four is the multi-focused implementation of CLIL. This stage includes preparing competent trans-disciplinary teachers, gaining cross-stakeholders' support, and selecting mixed strategies. The mixed strategies could be from four fields, that is, the content-language integrating strategies, general learning strategies, language learning strategies, and specific-subject learning strategies. Preparing competent transdisciplinary teachers refers to training the teachers to master trans-disciplinary knowledge and competence, such as content-related knowledge and competence, language-related competence, pedagogical content knowledge (PCK), and general competence. Attaining cross-stakeholders support means to get the support from both school-external stakeholders and school personnel.

Stage five is the multi-focused evaluation of CLIL. This consists of holistic evaluation objectives, cross-stakeholders as evaluators, and mixed evaluation techniques. Regarding the holistic evaluation objectives, evaluators need to evaluate other elements related to the curriculum in addition to students' learning (content, language, culture, cognition, affection, and skills). With regard to the mixed evaluation techniques, it has been argued to be related with evaluation objectives, including both qualitative and quantitative techniques. In addition to the multi-focused evaluation objectives and mixed evaluation techniques, the evaluators themselves form another aspect, as more feedback is needed to ensure a sufficient evidence-base to make secure judgments. Hence, there is an appeal for cross-stakeholders to participate in the evaluation of CLIL curricula, which may involve teachers, experts, officers from different disciplines, and even learners themselves.

Taken together, the holistic model for CLIL CD demonstrates the holism of CLIL, emphasizing the integration of each element in each stage of $\mathrm{CD}$. This model creates a dynamic theoretical and practiceoriented foundation for CLIL CD.

\section{CONCLUSION}

CLIL has undergone important development during the past years. The model of CLIL CD is significant as it can guide CLIL stakeholders to develop curriculum and research. Due to a lack of studies about this topic, this research has presented an overview of CLIL CD, which has led to the construction of a holistic model. According to CLIL features and Boyer's SOI, a holistic model of CLIL CD that was developed in this study is composed of five interacting stages with 15 elements. This model conveys the following key ideas: First, the process of CLIL CD should be transdisciplinary, not simply from language or 
content, but a fusion of these. Second, CLIL CD encourages all stakeholders to work in a team. Third, the elements for each stage of CLIL CD are interrelated, being integrative as a whole. In sum, this systematic review could help people to understand CLIL CD better in the context of the fragmented discussion in the broader field of school curriculum.

Nevertheless, as CLIL CD is inherently 'open', we do not contend a one-size-fits-all model. The holistic model presented here would need to be modified for application in a diversity of contexts. As well, we need to acknowledge that this literature review might be somewhat biased. One weakness is that the search term we used, which was limited to 'CLIL' and 'Content and Language Integrated Learning', may have excluded some related research that dealt with an alternative conceptualization of CLIL (e.g. teaching mathematics/history through/in English, immersion, English-media instruction, content-based instruction). In terms of the coverage, we chose English journal articles only and specific databases, which might also have imposed limitations on the conclusions we drew about the current research. Another limitation is the construction of the holistic model. Some expressions for each stage in CLIL CD are ambiguous, so it is challenging to extract the data based on some related labels. A future systematic review on CLIL CD could include literature published in non-English journals or elect one stage of CLIL CD for deeper analysis. We could also design empirical research to investigate the opinions about CLIL CD of stakeholders from different fields. We believe, the integration of mixed research design would result in a larger and clearer picture for CLIL CD.

\section{ACKNOWLEDGEMENTS}

This work was supported by the National Social Science Fund of China (NSSFC, Grant No. BHA180125) entitled 'Research on the Construction of Learning-Centered Assessment Theory', the Philosophy and Social Sciences Fund from Guangzhou entitled 'Study on Curriculum Development of Cultivating Interdisciplinary Foreign Language Talents in Guangzhou Higher Education Under the Background of One Belt, One Road Initiative' (Grant No. 2020GZGJ140), the Humanities and Social Science Project from the Ministry of Education of China (Grant No. 20YJC880005) entitled 'Study on Principles and Methods of Knowledge Creation in Outstanding Teachers Action Research', and the Innovation Fund of South China Normal University (Grant No. 19JKKA04) entitled 'A Study on the Acceptance of SAR by Teachers and Students in Rural Primary Schools'.

\section{REFERENCES}

[1] M. L. Perez-Canado, "CLIL Research in Europe: Past, present, and future," International Journal of Bilingual Education and Bilingualism, vol. 15, no. 3, pp. 315-341, 2012.

[2] D. Coyle, P. Hood, and D. Marsh, CLIL: Content and Language Integrated Learning. Cambridge: Cambridge University Press, 2010.

[3] S. Barboráková, "CLIL: Principles, skills and support strategies," Social \& Economic Revue, vol. 10, no. 4, pp. 7-11, 2012

[4] P. F. Oliva, Developing the Curriculum (5th Ed.). Boston: Allyn and Bacon, p. 23, 2001.

[5] A. N. Asomoza, "Students' perceptions of the impact of CLIL in a Mexican BA program," PROFILE: Issues in Teachers' Professional Development, vol. 17, no. 2, pp. 111-124, 2015.

[6] A. Wegner, "Seeing the bigger picture: What students and teachers think about CLIL," International CLIL Research Journal, vol. 1, no. 4, pp. 29-35, 2012.

[7] M. L. Falk, "English and Swedish in CLIL student texts," Language Learning Journal, vol. 43, no. 3, pp. 304-318, 2015.

[8] P. Ball, "Innovations and challenges in CLIL materials design," Theory into Practice, vol. 57, no. 3, pp. 222-231, 2018.

[9] D. L. Banegas, "Sharing views of CLIL lesson planning in language teacher education," Latin American Journal of Content \& Language Integrated Learning, vol. 8, no. 2, pp. 104-130, 2015.

[10] C. Dalton-Puffer, "Content-and-language integrated learning: From practice to principles," Annual Review of Applied Linguistics, vol. 31, pp. 182-204, Mar. 2011.

[11] R. Casan-Pitarch, "Project work in CLIL: A bibliographical review," Latin American Journal of Content \& Language Integrated Learning, vol. 8, no. 2, pp. 212-236, 2015.

[12] R. Serrano and I. Miralpeix, "Review of doctoral research on second language teaching and learning in Spain (2008-2010)," Language Teaching, vol. 46, no. 1, pp. 87-107, 2013

[13] S. Doff, F. G. Königs, N. Marx, and B. Schädlich, "Review of doctoral research in language education in Germany (2009-2013)," Language Teaching, vol. 49, no. 2, pp. 213-234, 2016.

[14] M. Dooly and D. Masats, "A critical appraisal of foreign language research in content and language integrated learning, young language learners, and technology-enhanced language learning published in Spain (2003-2012)," Language Teaching, vol. 48, no. 3, pp. 343-372, 2015. 
[15] L. Dale, R. Oostdam and M. Verspoor, "Searching for identity and focus: Towards an analytical framework for language teachers in bilingual education," International Journal of Bilingual Education and Bilingualism, vol. 21, no. 1 , pp. 1-18, 2017.

[16] C. Finkbeiner, A. M. Olson, and J. Friedrich, "A country in focus: Foreign language learning and teaching in Germany-A review of empirical research literature from 2005 to 2010," Language Teaching, vol. 46, no. 4, pp. 477-510, 2013.

[17] K. M. Graham, Y. Choi, A. Davoodi, S. Razmeh, and L. Q. Dixon, "Language and content outcomes of CLIL and EMI: A systematic review," Latin American Journal of Content and Language Integrated Learning, vol. 11, no. 1, pp. 19-37, 2018

[18] J. A. Goris, E. Denessen, L. Verhoeven, "Effects of content and language integrated learning in Europe A systematic review of longitudinal experimental studies," European Educational Research Journal, vol. 18, no. 6, pp. 675-698, 2019.

[19] G. E. Pawlas and P. F. Oliva, Supervision for Today's Schools. New Jersey: Wiley Global Education, 2007.

[20] E. L. Boyer, Scholarship Reconsidered: Priorities of the Professorate. Princeton, New Jersey: Carnegie Foundation for the Advancement of Teaching, pp. 18-19, 1990.

[21] J. Jesson, K. L. F. Matheson, and M. Lacey, Doing your Literature Review: Traditional and Systematic Techniques. London: Sage, pp. 209-211, 2011.

[22] D. Tranfield, D. Denyer, and P. Smart, "Towards a methodology for developing evidence-informed management knowledge by means of systematic review," British Journal of Management, vol. 14, no. 3, pp. 207-222, 2003.

[23] J. Wiles and J. Bondi, Curriculum Development: A Guide to Practice (Sixth Edition). New Jersey: Person Education, 2002

[24] A. C. Ornstein and F. P. Hunkins, Curriculum: foundation, Principles, and Issues. Boston: Pearson, 1988.

[25] S. I. Georgiou, "Reviewing the puzzle of CLIL," ELT Journal, vol. 66, no. 4, pp. 495-504, 2012.

[26] C. Dalton-Puffer and U. Smit, "Content and language integrated learning: A research agenda," Language Teaching, vol. 46, no. 4, pp. 545-559, 2013.

[27] M. C. Méndez García, "The intercultural turn brought about by the implementation of CLIL programmes in Spanish monolingual areas: A case study of Andalusian primary and secondary schools," Language Learning Journal, vol. 41, no. 3, pp. 268-283, 2013.

[28] G. B. Pérez, "Content and language integrated learning in the Catalan-speaking territories of Spain: Catalonia, the Valencian community and the Balearic Islands," European Journal of Language Policy, vol. 7, no.1, pp. 43-63, 2015.

[29] J. Rodriguez Bonces, "Content and language integrated learning (CLIL): Considerations in the Colombian context," GIST Education and Learning Research Journal, no. 6, pp.177-189, Nov. 2012.

[30] V. Vázquez, J. López, A. Gallego Segador, and R. Espejo Mohedano, "Strategic and organisational considerations in planning content and language integrated learning: A study on the coordination between content and language teachers," International Journal of Bilingual Education and Bilingualism, vol. 18, no. 4, pp. 409-425, 2015.

[31] M. R. Corinne, "Content and language integrated learning (CLIL): The influence of studying through English on Spanish students' first-language written discourse," Text \& Talk, vol. 30, no. 6, pp. 679-699, 2010.

[32] A. Bruton, "Are the differences between CLIL and Non-CLIL groups in Andalusia due to CLIL? A reply to Lorenzo, Casal and Moore (2010)," Applied Linguistics, vol. 32, no. 2, pp. 236-241, 2011.

[33] A. Bruton, "CLIL: Detail matters in the whole picture. More than a reply to J. Hüttner and U. Smit (2014)," System, vol. 53, pp. 119-128, Oct. 2015.

[34] L. Van Mensel, P. Hiligsmann, L. Mettewie, B. Galand, "CLIL, an elitist language learning approach? A background analysis of English and Dutch CLIL pupils in French-speaking Belgium," Language, Culture and Curriculum, vol. 33, no. 1, pp. 1-14, 2019.

[35] P. W. Juchacz, "The Scholarship of integration: On the pivotal role of centers of advanced study in the new structure of research-intensive universities in the 21st century," Czlowiek i Spoleczeństwo, no. 35, pp. 191-202, 2013.

[36] M. L. Pérez Cañado, "Are teachers ready for CLIL? Evidence from a European study," European Journal of Teacher Education, vol. 39, no. 2, pp. 202-221, 2016.

[37] D. Coyle, "Content and language integrated learning: Towards a connected research agenda for CLIL pedagogies," International Journal of Bilingual Education and Bilingualism, vol. 10, no. 5, pp. 543-562, 2007.

[38] D. Coyle, "Strengthening integrated learning: Towards a new era for pluriliteracies and intercultural learning," Latin American Journal of Content \& Language Integrated Learning, vol. 8, no. 2, pp. 84-103, 2015.

[39] W. A. Yitbarek, "Impact of enhanced input, pushed output, and inner speech on the accuracy of EFL learners under varying task complexities of content and language integrated learning," Science, Technology and Arts Research Journal, vol. 4, no. 3, pp. 230-239, 2015.

[40] L. Dale, R. Oostdam, and M. Verspoor, "Searching for identity and focus: Towards an analytical framework for language teachers in bilingual education," International Journal of Bilingual Education and Bilingualism, vol. 21, no. 1, pp. 1-18, 2018.

[41] R. Durán-Martínez, F. Beltrán-Llavador, and F. Martínez-Abad, "A contrastive analysis between novice and expert teachers' perceptions of school bilingual programmes," Cultura Y Educación, vol. 28, no. 4, pp. 738-770, 2016.

[42] M. L. Pérez Cañado, "Innovations and challenges in CLIL teacher training," Theory into Practice, vol. 57, no. 3, pp. 212-221, 2018. 
[43] Y. Ruiz de Zarobe and J. Cenoz, "Way forward in the twenty-first century in content-based instruction: Moving towards integration," Language, Culture and Curriculum, vol. 28, no. 3, pp. 90-96, 2015.

[44] A. Czura and K. Papaja, "Curricular models of CLIL education in Poland," International Journal of Bilingual Education and Bilingualism, vol. 16, no. 3, pp. 321-333, 2013.

[45] B. Yang, "Toward a holistic theory of knowledge and adult learning," Human Resource Development Review, vol. 2, no. 2, pp. 106-129, 2003.

[46] K. Suwannoppharat and S. Chinokul, "Applying CLIL to English language teaching in Thailand: Issues and challenges," Latin American Journal of Content \& Language Integrated Learning, vol. 8, no. 2, pp. 237-254, 2015.

[47] Y. Ruiz de Zarobe and V. Zenotz, "Reading strategies and CLIL: The effect of training in formal instruction," Language Learning Journal, vol. 43, no. 3, pp. 319-333, 2015.

[48] R. Wei and J. Feng, "Implementing CLIL for young learners in an EFL context beyond Europe," English Today, vol. 31, no. 1, pp. 55-60, 2015.

[49] L. C. Ravelo, "Demystifying some possible limitations of CLIL (content and language integrated learning) in the EFL classroom," Latin American Journal of Content \& Language Integrated Learning, vol. 7, no. 2, pp. 71-82, 2014.

[50] B. Mohan, Language and Content. Reading. Ma: Addison-Wesley, pp. 1, 1986. 